\title{
Thermally stimulated discharge conductivity in polymer composite thin films
}

\author{
V S SANGAWAR, P S CHIKHALIKAR*, R J DHOKNE, A U UBALE and \\ S D MESHRAM ${ }^{\dagger}$ \\ Department of Physics, Government Vidarbha Institute of Science \& Humanities, Amravati 444 604, India \\ ${ }^{\dagger}$ R. D. I. K. College, Badnera 444 701, India
}

MS received 9 June 2005; revised 16 June 2006

\begin{abstract}
This paper describes the results of thermally stimulated discharge conductivity study of activated charcoal-polyvinyl chloride (PVC) thin film thermoelectrets. TSDC has been carried out in the temperature range $308-400^{\circ} \mathrm{K}$ and at four different polarizing fields. Results are discussed on the basis of mobility of activated charcoal and polyvinyl chloride chains.
\end{abstract}

Keywords. TSDC; PVC; charcoal; thermoelectrets.

\section{Introduction}

Electrets formed by thermal methods are referred to as thermoelectrets. It is well known that in general, thermally stimulated discharge conductivity (TSDC) from thermoelectrets is considered to be induced by the thermal release of dipoles, ions and trapped electrons (Sangawar and Adgaonkar 1995). There are two approaches to make electrically conducting polymer composites: (i) use of conductive carbon black (fibres or particulate fillers) in appropriate lay up, doses and dispersions in an insulating polymer matrix to produce semiconducting or conducting reinforced or filled composites and (ii) use of an inherently conducting polymer intimately blended with or dispersed in a second polymer matrix (i.e. insulating in character) during or subsequent to synthesis (Ghosh 1997).

The present work belongs to category (i) and accounts for the experimental study relating to the behaviour of d.c. electrical conductivity in insulating polymer like PVC rendered semiconductive with filling of less amount of activated charcoal. Highly dispersed activated charcoal, giving sufficient conductivity at comparatively low concentrations, is used. The fine powder of graphite of 200 mesh size was dispersed in castor oil based polyurethanes composites (Srivastava et al 2002). The composite specimens prepared by compression molding technique were characterized for volume resistivity to find out electrical conductivity in the range of $10^{-13}(\mathrm{ohm} \mathrm{cm})^{-1}$.

These filled polymers have a number of advantages in terms of (i) absorbing the specific radiation, (ii) improving thermal stability, (iii) enhancing thermal and electrical

*Author for correspondence (pal102003@yahoo.co.in) conductivities, and (iv) reducing the cost and easy processability to achieve conductivity. The study of resistivity and thermal noise of amorphous polymers (polystyrene, polymethyl methacrylate, polyvinyl chloride) containing a small percentage of carbon black was reported by Klason and Kubat (1975). Time dependent resistivity was recorded in glass transition $\left(T_{\mathrm{g}}\right)$ and melting temperature $\left(T_{\mathrm{m}}\right)$ regions.

The TSDC technique is a basic tool to identify and evaluate the dipole reorientation process, trapping and recombination levels in electrets.

\section{Experimental}

\subsection{Preparation of samples}

The polyvinyl chloride (PVC) used was supplied by Reliance Industries, Mumbai and a fine activated charcoal was supplied by New Modern Chemical Corporation, Mumbai. The thin films of polymer composites i.e. (PVC + charcoal), were prepared in the laboratory by weight percent method with an accuracy of $0.0001 \mathrm{~g}$. Electronic single pan balance, Adiardutt-180, $0.9995 \mathrm{~g}$ of PVC was dissolved in cyclohexanone (AR grade), then $0.0005 \mathrm{~g}$ fine powder of activated charcoal was added in above solution for preparation of thin films of 0.05 weight percent of charcoal added PVC. After stirring this solution for many hours for maximum dispersion, the films were prepared by pouring the solution on a cleaned optically plane glass plate. This glass plate was kept over a pool of mercury for perfect levelling, so as to ensure uniform thickness and the solution was allowed to evaporate at room temperature. Then after complete evaporation, the 
film was detached from glass surface. In this way the films were prepared by solution evaporation technique. Same procedure was adopted for 0.5 weight percent charcoal added PVC thin films (Sangawar 1996; Belsare and Deogaonkar 1998). These films were subjected to $12 \mathrm{~h}$ heating at a constant temperature of $40^{\circ} \mathrm{C}$ and for another $12 \mathrm{~h}$ at room temperature to remove the traces of solvent.

\subsection{Thickness measurement}

For measuring the thickness, micrometer screw gauge with a least count of $0.001 \mathrm{~cm}$ was used but for greater accuracy and resolution a compound microscope in conjunction with an occulometer which had least count $(15.38 \mu \mathrm{m})$ at the magnification of $1: 100$ was used (Belsare and Deogaonkar 1998). A small section of the sample was taken and mounted vertically to get clear sectional view of pure PVC and composite. The thickness of the film was $48 \cdot 14$ and $61.52 \mu \mathrm{m}$ for pure PVC and composite, respectively.

\subsection{Electrode coating}

For good ohmic contact, both the surfaces of film were coated by quick drying and highly conductive silver paint supplied by Eltecks Corporation, Bangalore.

\subsection{Electret preparation}

The coated film was sandwiched between the two brass electrodes. The sample holder forming metal-polymermetal system was placed in a furnace and heated up to the poling temperature of $348^{\circ} \mathrm{K}$. The sample was allowed to remain at that temperature for about $30 \mathrm{~min}$. Then electric field of desired strength was applied for $1 \mathrm{~h}$ at poling temperature with the applied electric field. The sample was allowed to cool down at room temperature, $301^{\circ} \mathrm{K}$ in the presence of applied field. Total time of polarization was adjusted to be $2 \mathrm{~h}$ in each case. On attaining room temperature, the samples were kept shorted for 20 min to eliminate the stray charges. The electrets were prepared at different d.c. polarizing fields: $E=0.324 \mathrm{kV} / \mathrm{cm}$, $0.649 \mathrm{kV} / \mathrm{cm}, 1.299 \mathrm{kV} / \mathrm{cm}, 1.623 \mathrm{kV} / \mathrm{cm}$, respectively.

\subsection{Measurement of thermally stimulated discharge conductivity}

After electret formation, the sample holder assembly was placed in a controlled temperature furnace supplied by Pushpa Scientifics, Hyderabad. The d.c. electrical conductivity was measured by determining the resistance of a sample within temperature range $308-400^{\circ} \mathrm{K}$ at the rate of $2 \% \mathrm{~min}$. The temperature was recorded by a digital thermometer having an accuracy of $+1^{\circ} \mathrm{C}$. A digital multimeter (systronics, 435) having an accuracy of $\pm 1 \mathrm{mV}$ was used for the measurement of voltage drop across high resistance. The method used for conductivity measurement was the same as that reported earlier (Kher and Adgaonkar 1972).

\section{Results and discussion}

The results of the present study are in the form of thermograms (figures 1-3) which are curves between $\log$ of thermally stimulated discharge conductivity, $\sigma(\mathrm{mho} / \mathrm{cm})$ and temperature $\left(10^{3} / T\right)$ of the sample films at different polarizing fields.

The thermograms of figure 1 are of pure PVC film. For all polarizing fields, the d.c. conductivity is in insulating order. Figures 2 and 3 show that the PVC was rendered semiconductive by addition of 0.05 and 0.5 weight percent of activated charcoal. The slight decrease is observed at low temperature and continuous increase is observed up to $423^{\circ} \mathrm{K}$ in all the samples. A nonlinear field dependence is clearly evident in pure and filled PVC samples.

The constituent of pure film, viz. PVC, is largely an amorphous polymer. It is characterized by three relaxations: $\beta$ relaxations occurring at low temperature, $\alpha$ relaxation around the glass rubber transition temperature $\left(T_{\mathrm{g}}\right)$ and $\alpha_{1}$ relaxation occurring at a temperature well above $T_{\mathrm{g}}$. The absence of peaks in the present thermograms might be due to low applied electric field.

In polymeric materials, various types of molecular relaxations are possible. The only motions possible at a low temperature are local motions of molecular groups, e.g. rotation of side groups or internal motion within the side groups. Hence at low temperature there may be slight decrease and then rise in conductivity of thermoelectret of pure PVC films. This is due to mobility of main chain segment increase with the increase in temperature.

Figures 2 and 3 represent thermograms $\left(\log \sigma\right.$ vs $10^{3} / T$ plot) of 0.05 and 0.5 weight percent activated charcoal added PVC thin film thermoelectrets for different polarizing fields $(0.324 \mathrm{kV} / \mathrm{cm}, 0.649 \mathrm{kV} / \mathrm{cm}, 1.299 \mathrm{kV} / \mathrm{cm}$, $1.623 \mathrm{kV} / \mathrm{cm})$. In both the cases the conductivity increases with increasing temperature i.e. semiconducting nature of thermoelectret. Our experimental study revealed that electrical conductivity increases with the increase in temperature approximately by the following equation

$$
\sigma=\sigma_{0} \exp \left(-E_{0} / K T\right)
$$

where $\sigma$ is conductivity, $\sigma_{0}$ the pre-exponential factor, $E_{0}$ the activation energy of conduction and $K$ the Boltzmann's constant. The activation energy, $E_{0}$, was calculated from the graph of $\log \sigma$ vs $10^{3} / T$ plot. Tables $1-3$ show the variation of activation energy values within low, intermediate and high temperature regions.

Addition of charcoal increases the conductivity of polymer considerably (figures 2 and 3). As the percentage of loading is only 0.05 weight percent in second case, smooth 


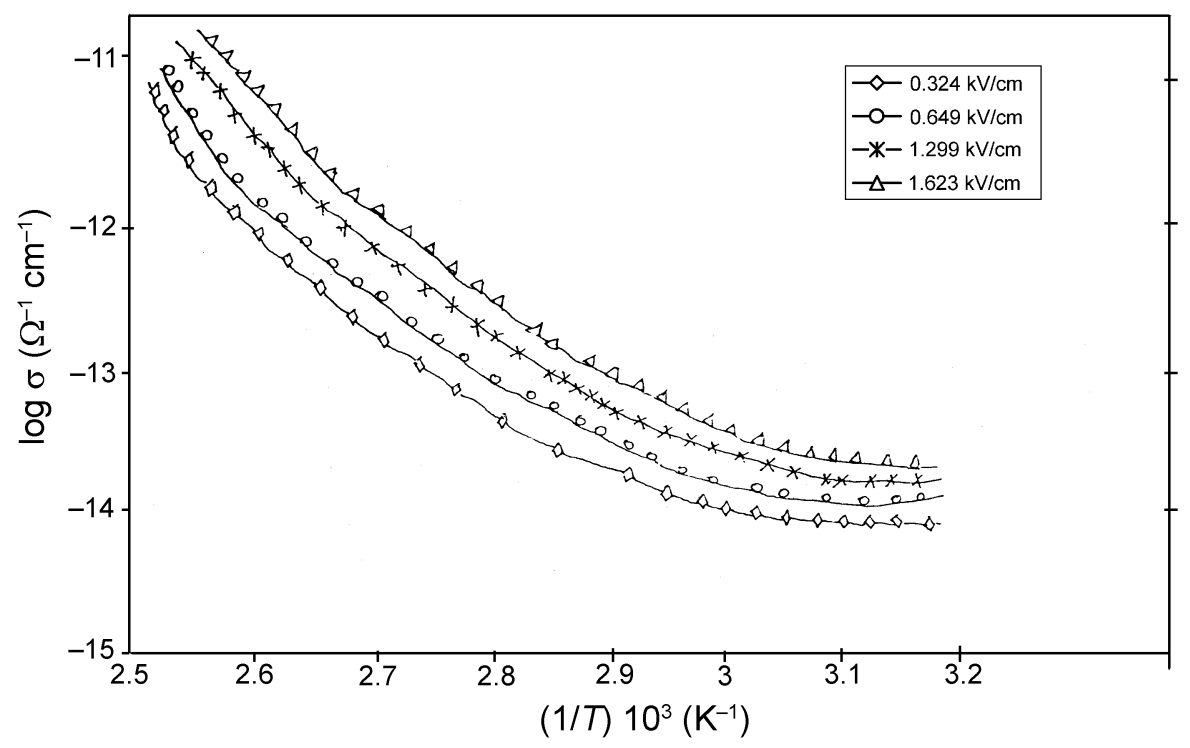

Figure 1. Pure PVC plot of $10^{3} / T\left(\mathrm{~K}^{-1}\right)$ vs $\log \sigma\left(\Omega^{-1} \mathrm{~cm}^{-1}\right)$.

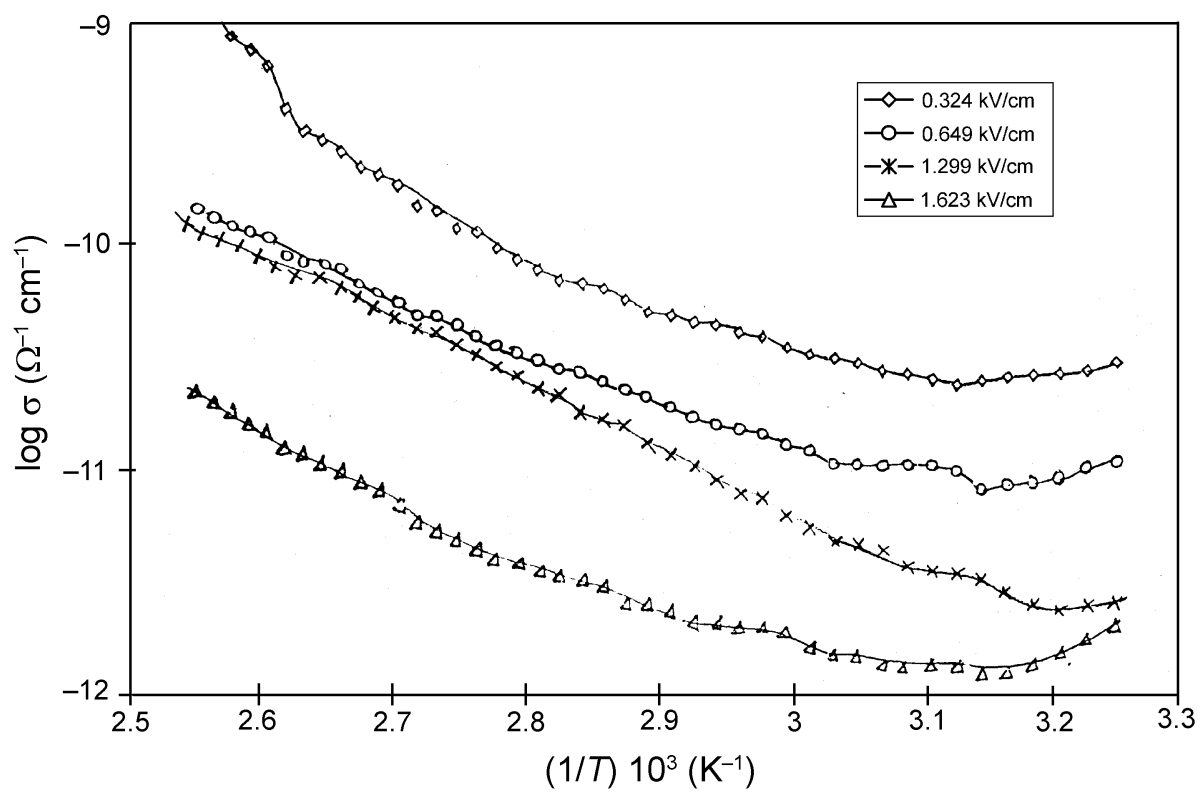

Figure 2. $0.05 \% \mathrm{CB}$ doped PVC plot of $\log \sigma$ vs $(1 / T) 10^{3}\left(\mathrm{~K}^{-1}\right)$.

increase was observed. Initially increase in conductivity at low temperature may be due to the injection of charge carriers directly from the electrodes. The filler is very sensitive to temperature. There are two phases i.e. polymer phase and filler phase. They formed heterocharges and discharge by dipole disorientation is thermally activated and so can be speeded up by heating. The increase in conductivity at higher temperature may be due to softening, the injected charge carrier can move more easily into the volume of the sample giving rise to a large current and increase in conductivity at higher temperature.
In the third case, as shown in thermogram 3, the loading of activated charcoal slightly increased from $0 \cdot 05-0.5$ weight percent. There is a slight change in conductivity, $\sigma$, for these samples especially at higher temperature above $T_{\mathrm{g}}$. As the temperature increases, the chain of the PVC becomes more and more flexible. This conduction is mainly due to a direct contact with charcoal particle as explained by Ateia (1998).

The increase in conductivity with temperature at a sensitively low field is due to the increase in the magnitude of the mean free path of phonon (Gwaily et al 1993). At 


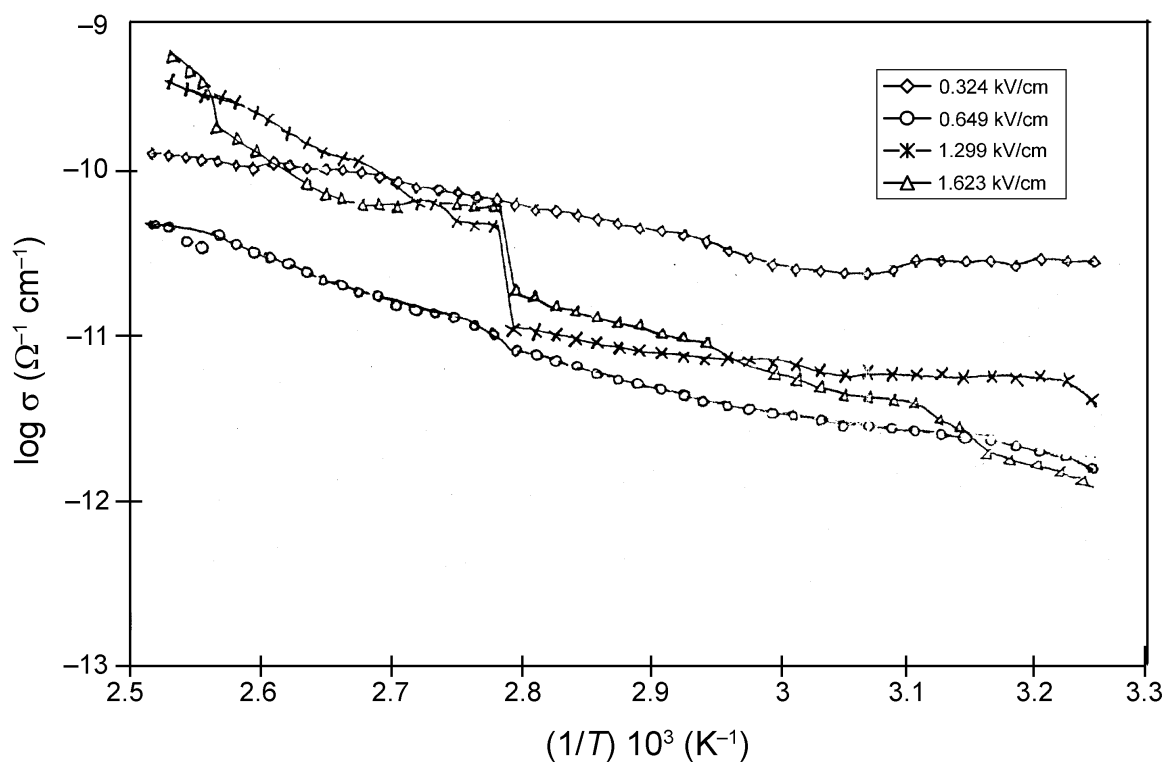

Figure 3. $0 \cdot 5 \% \mathrm{CB}$ doped PVC plot of $\log \sigma$ vs $(1 / T) 10^{3}\left(\mathrm{~K}^{-1}\right)$.

Table 1. Variation of activation energy, $E_{0}$, in the three temperature regions for pure PVC thin film.

\begin{tabular}{lccc}
\hline $\begin{array}{l}\text { Polarizing field } \\
(\mathrm{kV} / \mathrm{cm})\end{array}$ & Region I & Region II & Region III \\
\hline 0.324 & $1.038 \mathrm{eV}$ & $1.123 \mathrm{eV}$ & $1.446 \mathrm{eV}$ \\
0.649 & $1.024 \mathrm{eV}$ & $1.213 \mathrm{eV}$ & $1.324 \mathrm{eV}$ \\
1.299 & $1.012 \mathrm{eV}$ & $1.310 \mathrm{eV}$ & $1.214 \mathrm{eV}$ \\
1.623 & $0.058 \mathrm{eV}$ & $1.115 \mathrm{eV}$ & $1.156 \mathrm{eV}$ \\
\hline
\end{tabular}

Table 2. Variation of activation energy, $E_{0}$, in the three temperature regions for $0.05 \%$ activated charcoal doped PVC.

Polarizing field

\begin{tabular}{llcc}
$(\mathrm{kV} / \mathrm{cm})$ & Region I & Region II & Region III \\
\hline 0.324 & $0 \cdot 235 \mathrm{eV}$ & $0.495 \mathrm{eV}$ & $0.705 \mathrm{eV}$ \\
0.649 & $0 \cdot 165 \mathrm{eV}$ & $0.435 \mathrm{eV}$ & $0.640 \mathrm{eV}$ \\
1.299 & $0 \cdot 340 \mathrm{eV}$ & $0.555 \mathrm{eV}$ & $0 \cdot 800 \mathrm{eV}$ \\
1.623 & $0 \cdot 170 \mathrm{eV}$ & $0.400 \mathrm{eV}$ & $0.950 \mathrm{eV}$ \\
\hline
\end{tabular}

Table 3. Variation of activation energy, $E_{0}$, in the three temperature regions for $0.5 \%$ activated charcoal doped PVC.

\begin{tabular}{llll}
\hline $\begin{array}{l}\text { Polarizing field } \\
(\mathrm{kV} / \mathrm{cm})\end{array}$ & Region I & Region II & Region III \\
\hline 0.324 & $0 \cdot 240 \mathrm{eV}$ & $0.250 \mathrm{eV}$ & $0.125 \mathrm{eV}$ \\
0.649 & $0 \cdot 145 \mathrm{eV}$ & $0.430 \mathrm{eV}$ & $0.315 \mathrm{eV}$ \\
1.299 & $0.440 \mathrm{eV}$ & $0.465 \mathrm{eV}$ & $0.410 \mathrm{eV}$ \\
1.623 & $0.040 \mathrm{eV}$ & $0.250 \mathrm{eV}$ & $0.700 \mathrm{eV}$ \\
\hline
\end{tabular}

high temperature enhancement in conductivity is mainly attributed to the increase in ionic mobility of activated charcoal particles (Ramadin et al 1993). Our results are in good agreement with Ateia (1998), Gwaily et al (1993) and Ramadin et al (1993).

\section{Conclusions}

Thus the present study reveals that both the temperature and addition of activated charcoal influence the conductivity of PVC. This filled PVC polymer could be good for low cost semiconducting composites.

\section{Acknowledgement}

The authors are very much thankful to Dr S A Ghosh, Department of Physics, Government Vidarbha Institute of Science and Humanities, Amravati, for laboratory facilities.

\section{References}

Ateia E 1998 J. Polym. Mater. 15403

Belsare N G and Deogaonkar V S 1998 J. Polym. Mater. 15157

Ghosh P 1997 J. Polym. Mater. 14193

Gwaily S E, Attia G, Nasr G M and Hassan H H 1993 J. Polym. Mater. 10221

Kher V G and Adgaonkar C S 1972 Indian J. Pure \& Appl. Phys. 10902

Klason Carl and Kubat Josef 1975 J. Appl. Polym. Sci. 19831

Ramadin Y, Ahmed M, Jawad S A and Zihlif A 1993 J. Polym. Mater. 10251

Sangawar V S 1996 D.C. electrical conductivity study of polystyrene and polymethyl methacrylate iodine doped thermoelectrets, Ph.D. Thesis, Amravati University, Amravati

Sangawar V S and Adgaonkar C S 1995 J. Polym. Mater. 1211 Shrivastava A, Chauhan R C and Singh P 2002 Indian J. Engg. Mater. Sci. 197 